\title{
Nietzsche e Strindberg: o encontro de duas almas à parte
}

\author{
Patrick Attali*
}

\begin{abstract}
Resumo: Este artigo visa a destacar o interesse filosófico da correspondência entre Nietzsche e Strindberg. Os seus percursos se entrecruzam graças a uma comunhão de opiniões sobre assuntos essencialmente polêmicos: dessa forma, eles questionam os ideais modernos de emancipação feminina. Para mostrar o sentido deste combate delicado, examinamos a controvérsia que Strindberg trava contra uma peça de Ibsen, Uma casa de boneca. Com esta análise, é-nos possível avançar uma interpretação de uma grande tragédia de Strindberg (Pai), de conceber nitidamente o alcance propriamente nietzschiano dela e de mostrar enfim os limites da convergência intelectual dos dois homens.
\end{abstract}

Palavras-chave: cartas - combate - feminismo - teatro - literatura.

Eis o acontecimento: Nietzsche (1844-1900) e Strindberg (1849-1912) trocam cartas nos finais de 1888. Aquela "correspondência fulgurante" , poderia ser vista, por pouco que se cedesse a um certo exagero, como um fato notável das Letras Europeias. Um filósofo alemão e um grande escritor sueco se explicam. A relação epistolar parece ser a oportunidade para uma revelação.

* Tradução de Marie-Christine Lescure.

** Professor da Université de Rouen, Rouen, França. E-mail : attali.pat@orange.fr. Gostaria de manifestar o meu profundo reconhecimento à senhora Marie-Christine Lescure. Ela não foi apenas uma tradutora. Ela teve o cuidado permanente de aperfeiçoar a formulação do pensamento, tanto na versão francesa, quanto na brasileira. Este artigo lhe deve muito.

1 PERELLI F. Strindberg: l'expérience du surhomme. In Strindberg, Cahier de l'Herne sob a direção de E. Balzamo, Edições de l'Herne, 2000, p. 138. 
Attali, P.

Mas o que revela na realidade? Não é evidente sabê-lo à primeira vista. Os sinais de conivência que se enviam são bastante difíceis de interpretar: as cartas são cada vez mais curtas. $\mathrm{O}$ estilo é frequentemente lacônico; seus objetivos nos deixam perplexos. Para apreciarmos o caso a sério, é preciso voltar a estudá-lo. Os conhecedores de Strindberg parecem poder ajudar-nos. Num número especial da revista francesa Le Cahier de l'Herne, dedicado ao escritor sueco, eles debruçaram-se sobre a questão. Mas procuraram sobretudo mostrar como Strindberg poderia ter sido influenciado por suas leituras de Nietzsche. São então preocupações de comentadores que prevaleceram na apreciação do encontro.

No que nos concerne, entendemos dar um particular cuidado ao exame da perspectiva propriamente nietzschiana. Contudo, a via fica ainda por traçar. Segundo um dos biógrafos mais sério do filósofo, o contato teria ficado globalmente "infecundo" ${ }^{\text {. Curt-Paul }}$ $\mathrm{Janz}^{3}$ inspira-se neste propósito, das conclusões de Karl Strecker, autor de um pequeno livro dedicado à correspondência dos dois homens. Ora, algumas informações tiradas daquela obra tiveram mais tarde de ser corrigidas ${ }^{4}$, o que nos deve incitar à prudência. Por outro lado, o ponto de vista que tanto inspira Strecker como Janz, poderia ter sido demasiadamente influenciado pelo julgamento retrospectivo do próprio Strindberg. No crepúsculo de sua vida, ele não dá mais crédito a seu diálogo epistolar com Nietzsche. Vai até retratar-se ${ }^{5}$ pessoalmente. Assim, em outubro de 1909, quando volta a editar uma das suas antigas obras de caráter autobiográfico,

2 JANZ, Curt Paul. Nietzsche. Biographie. Edições Gallimard NRF 1985, tomo III, p. 368.

3 JANZ, Curt Paul. Op. cit., p. 597, nota $n^{\circ} 67$.

4 Elena BALZAMO, responsável do Cahier de l'Herne consagrado a Strindberg, nota que a publicação em questão (STRECKER Karl, Nietzsche und Strindberg. Georg Müller Verlag, 1921), embora "pioneira para a época, (...) é incompleta e comporta alguns erros de datação" (Strindberg, Cahier de l'Herne. Op. cit., p. 147).

5 Carta de Strindberg a Karl Strecker, de 30 de janeiro de 1909. In Strindberg, Correspondance complète tomo III, trad. Elena Balzamo, Edições Zulma 2012, pp. 442-443. 
já não se reconhece naquela obra escrita em 1886: "a personalidade do autor é-me então tão alheia - e antipática - como o pode ser aos olhos do leitor."6

Tudo isso nos convida a retomar completamente o exame da questão. As circunstâncias devem, primeiro, ser esclarecidas. Nos finais de 1888, Nietzsche vive em Turim; Strindberg, depois da sua estada na França, reside provisoriamente na Dinamarca. É graças a Georg Brandes, o eminente intelectual dinamarquês, que vão ouvir falar um do outro. De fato, Brandes corresponde-se com ambos. Aconselhado por Brandes, Nietzsche toma conhecimento das obras do sueco. Descobre os relatos agrupados sob o título de Casados!?. Por outro lado, na mesma altura, Nietzsche lê "duas vezes com profunda emoção" ${ }^{\text {Pai }}$, drama de Strindberg cuja importância também lhe tinha sido revelada por Brandes ${ }^{10}$. Enfim, pouco antes da interrupção de sua correspondência, Strindberg manda Remorsos diretamente a Nietzsche no dia 27 de dezembro de $1888^{11}$.

$\mathrm{O}$ que se pode dizer de Strindberg? Ele já conhecia o pensamento de Nietzsche. Segundo Elena Balzamo, Strindberg teria lido,

6 STRINDBERG. Obra Autobiográfica tomo II, Mercure de France 1990, p. 1174, tradução modificada.

7 Trata-se de uma versão primitiva desta obra que não leva em conta a segunda parte que Strindberg acrescentou mais tarde. Nietzsche evoca aquela versão primitiva em termos muito admirativos: “(...) li, com encanto e como se estivesse em casa, Casados de M. August Strindberg. A minha sincera admiração que nada vem perturbar senão o sentimento de me admirar um pouco a mim próprio ao mesmo tempo..." (Carta de Nietzsche a G. Brandes $\mathrm{n}^{\circ} 1151$ de 20 de novembro de 1888 KGB III/5.483). A edição francesa que será citada na continuação do artigo é a seguinte: Mariés ! I - Douze histoires de mariages avec interview et préface [Casados! I - Doze histórias de casamentos com entrevista e prefácio] (1884). Trad. Pierre Morizet e Eva Ahlstedt Ed. Actes Sud, 1986, pp. 33-201.

8 Carta de Nietzsche a Strindberg de 27 de novembro de 1888 in Nietzsche Últimas cartas Inverno 1887- Inverno 1889, p.188.

9 August Strindberg, Pai e Pária, tradução francesa de Georges Loiseau, precedida de uma carta de Emile Zola a Strindberg de 14 de dezembro de 1887, Paris 1888.

10 Cartas de Brandes a Nietzsche de 16 de Novembro de 1888 (nº66, KGB III/6.353) e de 23 de novembro de 1888 ( ${ }^{\circ} 612$, KGB III/6.361).

11 Carta de Strindberg a Nietzsche ( $\left.{ }^{\circ} 639\right)$, KGB III/6.405-406 \& Strindberg, Cahier de l'Herne. Op. cit., p. 151. Cf: Remorsos In: STRINDBERG, August. Utopies dans la réalité. Trad. Balzamo et Morizet. Arles, Actes Sud, 2003, pp. 187-240. 
Attali, P.

logo a partir de 1886, Para além do bem e do mal, e, em 1887, a Genealogia da moral ${ }^{12}$. Também descobriu, em 1888, O caso Wagner $^{13}$ assim como o Crepúsculo dos ídolos ${ }^{14}$. Strindberg era de fato políglota. Em resumo, os dois homens reconheceram-se através de suas respectivas obras. Em suas cartas, vemo-los se congratularem mutuamente. $\mathrm{O}$ interesse que apresenta o exame da correspondência entre os dois homens se delimita. Para o ver bem, é preciso se admirar de um "pormenor".

Nietzsche examina as obras de Strindberg muito tardiamente, depois de ter redigido os seus mais importantes textos, principalmente na altura da fase de revisão de Ecce homo ${ }^{15}$. O ritmo da correspondência com Strindberg, principiada em 27 de novembro, intensifica-se gradualmente até princípios do ano seguinte, ou seja, nas últimas semanas da vida lúcida do filósofo, mesmo logo antes do seu "colapso" de Janeiro de 1889. Ora, apesar de uma agenda muito carregada, o filósofo arranja tempo para ler aquele escritor e para lhe comunicar seus sentimentos e suas ideias. Sabendo que, por outro lado, ele estima não ter tempo para perder, em particular com correspondentes importunos ${ }^{16}$, a questão merece ser posta: por que razão se dedicar àquilo? Como forma de resposta, propomos algumas perspectivas de leitura da relação entre os dois, explorando os segundos planos desse encontro.

$*$

O parentesco dos objetivos de um e de outro pode se explicar primeiro porque têm consciência, nos finais dos anos 1880, de

12 BALZAMO E. In: Strindberg, Le sacristain romantique de Rånö. Posfácio (O órgão de sonho de Alrik), Ed. Viviane Hamy, 1999, p. 91.

13 Carta de Strindberg a G. Brandes de 2 de outubro de 1888. In Strindberg, Correspondance II, trad. Elena Balzamo, op. cit., p. 212 (e nota $n^{\circ} 196$ p. 486).

14 Carta de Nietzsche a Strindberg ${ }^{\circ} 1154$ a de 24 de novembro de 1888.

15 HÉMERY, Jean-Claude. Notes et variantes de Ecce homo. In : Nietzsche: L'Antéchrist suivi de Ecce homo, Éditions Gallimard 1974, p. 281.

16 Carta de Nietzsche a Overbeck n 1066 de 20 de julho de 1888, KGB III/5.361.

308 I Cad. Nietzsche, São Paulo, v.36 n.1, p. 305-319, 2015. 
viverem um momento crucial de sua existência. Nos difíceis combates que travam contra as tendências de sua época, estabelece-se uma solidariedade mútua: a solidariedade de dois anticonformistas que, dessa maneira, saem de certo isolamento. Num outro nível de análise, aprofundando o nosso ponto de vista, devemos tentar adivinhar as motivações do filósofo. É provável que a entrada em cena do sueco fosse concebida no quadro de uma estratégia global.

Naquela época, o autor do Crepúsculo dos ídolos é cada vez mais inspirado por um grande projeto de futuro. Ele resume a pesada missão à qual se dedica por esta notável fórmula: "a transmutação de todos os valores [Umwerthung aller Werthe]" (GD/CI, Prefácio, KSA 6.57). A reforma da cultura exige essa transmutação. A coisa é apresentada como "uma faina incomensuravelmente pesada e decisiva" 17 , cujos contornos se precisam cada vez mais nitidamente. Ela está revestida das cores sombrias de uma obra trágica. No prefácio do Crepúsculo dos ídolos, Nietzsche evoca "um caso tenebroso cuja responsabilidade ultrapassa todos os limites", tal "um ponto de interrogação (...) tão negro, tão formidável que estende a sua sombra em cima de quem o põe" (GD/CI, Prefácio, KSA 6.57). Sua carta de 14 de setembro de 1888 dá-nos outra imagem: Nietzsche diz que aquela faina, "se for entendida, dividirá em duas metades a história da humanidade."18

O autor do Crepúsculo dos ídolos propõe então "começar uma intervenção reformadora de natureza prática"19 a fim de desestabilizar o fundamento dos valores milenares de essência cristã, sobre o qual se edificou a civilização moderna. A aposta é operar a prazo uma completa mudança dos critérios de avaliação na base dos quais os homens se apoiaram para estimar toda coisa. Tal é a finalidade do que Nietzsche chama sob outro ponto de vista, " $a$ grande política" (Nachlass/FP, 1888, 25[1], KGW VIII-3.451).

17 Carta de Nietzsche a Paul Deussen $n^{\circ} 1111$ de 14 de setembro de 1888, KGB III/5.426.

18 Carta de Nietzsche a Paul Deussen $n^{\circ} 1111$ de 14 de setembro de 1888, KGB III/5.426.

19 WOTLING, P. Introduction au Crépuscule des idoles. Paris: Edição Flammarion, 2005, p. 109. 
Attali, P.

Um dos princípios deste eminente combate é a criação de um "partido da vida", partido que seria suficientemente poderoso para fazer "da fisiologia a rainha de todas as outras questões" (Nachlass/ FP, 1888, 25[1], KGW VIII/3.452). Um partido que seria então "suficientemente forte para içar a Humanidade, como um todo superior, com uma dureza sem complacência, contra tudo o que há de degenerado e de parasita na vida" (Nachlass/FP, 1888, 25[1], KGW VIII/3.452). No quadro dessa empresa, Nietzsche pensa ter necessidade de "mãos piedosas - de mãos imortais ! - e inúmeras" (Nachlass/FP 1888, 25[11], KGW VIII-3.456).

Em função dessas preocupações, o interesse que Nietzsche manifesta por Strindberg tem uma explicação: o escritor sueco é visto como a peça-chave naquele jogo estratégico. De fato, entre as coisas que o filósofo contesta, há notadamente certos ideais e certos ídolos aos quais é muito delicado se atacar frontalmente. Para conseguir esquivar tal dificuldade, mas tratando o problema de fundo, Strindberg parece-lhe ser um aliado «providencial». $O$ objetivo é pôr radicalmente em causa a idolatria contemporânea da «mulher» ${ }^{20}$, a do "amor", paralelamente a tudo o que o filósofo chama de "ideias modernas". Nietzsche contesta a pertinência do movimento moderno de emancipação feminina. $O$ caso revela-se delicado.

Ora, ao longo de suas leituras, ele se dá conta de um fato: o escritor sueco se diferencia de seus contemporâneos por seu espírito de independência e sua desconfiança para com as ideias em voga. Um homem assim não perde sua lucidez quando aborda a questão feminina. Seu talento de escritor lhe permite se exprimir de maneira radicalmente crítica. Eis o que interessa muito Nietzsche. É na sua vigorosa oposição ao escritor norueguês Henrik Ibsen (1828-1906) que os dois se encontram. Nietzsche fala dele

20 A título de ilustração, é preciso notar que seis das quarenta e quatro máximas da primeira seção do Crepúsculo dos ídolos questionam, mais ou menos diretamente, e com mais ou menos violência, a idolatria da mulher.

310 | Cad. Nietzsche, São Paulo, v.36 n.1, p. 305-319, 2015. 
num tom de escárnio em Ecce homo. Por seu lado, Strindberg está abertamente em conflito com Ibsen.

O exame a sério do ponto de vista de Strindberg exige de nossa parte uma mudança de registro: o nosso autor não é um puro teórico, mas antes um homem de letras e um crítico. É então por meio da análise literária que é possível evidenciar a originalidade de sua reflexão. Ele se concentra em particular em um drama burguês de Ibsen: Uma casa de bonecas (1879). De que se trata? A cena ibseniana oferece-nos a visão de uma mulher nova, "vivaz e sorridente", mas também astuta, manipuladora e um tanto extravagante: Nora, a esposa do banqueiro Helmer. Helmer é apresentado como um cabeça de família preocupado com sua carreira e suas prerrogativas.

Depois de oito anos de vida comum, o casal está aparentemente unido por amor. Contudo, se vivem agora abastados, não foi sempre o caso. Pequenas ambiguidades chamam então a atenção. A curiosidade é atiçada particularmente por uma confissão: no primeiro ato, Nora confessa a uma amiga ter cometido algo repreensível para se elevar à sua brilhante situação atual, principalmente uma falsificação de documento oficial. A intenção era louvável. Tratava-se de obter um empréstimo a fim de salvar o marido, na altura gravemente doente. Em virtude das leis em vigor na época, a mulher casada era privada de autonomia financeira. Para dispor rapidamente do dinheiro necessário à cura do marido, Nora então imitou a assinatura do pai. A divulgação deste ato, que Helmer desconhece totalmente, seria capaz agora de irritá-lo e arruinar sua fama, quando acabava de ser promovido à direção de seu banco. Mas, nesse meio tempo, Nora é vítima de chantagem por parte de uma personagem equívoca. A partir daí, ela se sente partilhada entre, por um lado a esperança de que o marido compreenda suas razões e a perdoe ${ }^{21}$, e, por outro lado, o receio do rancor que ele poderia ter a seu encontro.

21 Cf. IBSEN, Henrik. Une maison de poupée. Trad. R. Boyer. Paris: Gallimard, 2006-2013 
Attali, P.

No final de uma intriga bastante complicada, é o desfecho imprevisto da disputa conjugal que prepara o golpe teatral. Helmer reage sem magnanimidade frente à descoberta dos segredos de sua esposa: o desfecho do final da peça parece revelar nele uma aspiração um tanto mesquinha em vê-la submetida às exigências de sua própria carreira. Mas é nesse momento que Nora toma, de maneira teatral, a decisão de emancipar-se. Ela diz ter tomado consciência da grande falta de consideração de que fora vítima até então. Um pouco como Sócrates, ela quer se conhecer melhor a si própria. Julgando que foi considerada, por seu pai e por seu marido, como uma boneca, "decide abandonar sua casa de boneca, seu marido, seus filhos, sua vida burguesa", para ir embora "perseguir seu ideal de liberdade e de sinceridade" ${ }^{\prime 22}$.

O que faz exatamente Strindberg? Questiona a autenticidade das personagens criadas por Ibsen: segundo ele, a profunda coerência psicológica delas fica comprometida por uma vontade latente do autor. Querendo fazer a apologia da mulher, procurando comover o público sobre sua submissão jurídica a tutores masculinos, Ibsen quisera mostrá-la de maneira tal que parecesse injustamente oprimida. Ora, essa orientação não é sem consequências. Para formulá-las, o autor de Casados! adota um ponto de vista completamente oposto ao que prevaleceu no público: baseando-se na análise dos subentendidos das duas personagens, reavalia o valor moral delas. Em vez de ver em Nora uma vítima, e em Helmer um tirano mesquinho, afirma que uma grande injustiça foi cometida contra a personagem masculina. Segundo Strindberg, não é tanto o esposo que é culpado por tratar sua companheira como uma boneca: é, antes, a esposa que tem tendência em considerar o marido como sua grande boneca, ou seja, como um ser à custa de quem brinca e que gosta de manobrar.

- Resumo de Régis Boyer, p. 287.

22 Resumo de Régis Boyer, op. cit., p. 287.

312 | Cad. Nietzsche, São Paulo, v.36 n.1, p. 305-319, 2015. 
De fato, Nora se compraz demasiadamente na intriga e na mentira. A partir daí, "a peça prova exatamente o contrário do que supostamente deveria provar." 23

Da mesma maneira com que Nietzsche critica a tendência da ópera wagneriana (WA/CW 11, KSA 6.38) em conquistar o favor das massas, renunciando à exigência de integridade artística, o escritor sueco denuncia os artifícios dum certo teatralismo. Para agradar seu público, Ibsen sacrificaria resolutamente o rigor psicológico. Recorreria a duvidosos arcanos, em particular na cena final: seu objetivo seria levar o espectador a ver as duas figuras-chave de maneira excessivamente simplificadora. Assim faria com que o público esquecesse completamente as ambiguidades morais da heroína, se entusiasmasse por ela e se aliasse incondicionalmente à sua repentina "sabedoria socrática".

O preconceito favorável à Nora se iria formando ao longo de uma hábil manipulação dos espíritos: enquanto a hipótese de uma reconciliação fosse mais conforme a lógica do amor, o qual não desaparece tão facilmente segundo Strindberg, o escritor norueguês prefere provocar um efeito sensacional. Ele mostraria assim ao público estupefato uma mulher que decide, de maneira impressionante, cortar com o passado. O epílogo deve, de fato, tocar na alma do espectador como um disparo que atordoa todo o espírito crítico: «Zás! Isso é que é preciso quando cai a cortina! Nora prova (?) então que foi uma boneca!» ${ }^{24}$. Tudo seria então feito para ficarmos comovidos e até indignados sem nos interrogarmos sobre o significado complexo da emoção que sentimos na realidade. De fato, para o simples espectador, essas manipulações todas do sentimento não são visíveis. É preciso ler a peça a fundo, refletir nela calmamente, para adivinhar aquela "maquinação".

23 STRINDBERG. Mariés! Ed. Actes Sud, 1986, p. 18.

24 STRINDBERG. Mariés!, op. cit., p. 17. 
Strindberg aprofunda sua análise. Segundo ele, Ibsen teria composto a figura da heroína a fim de dar uma resposta sedutora às aspirações de seu público, já inclinado a aderir às teses feministas. Em consequência, a personagem de Nora constitui uma espécie de "esfinge", um ser totalmente híbrido. Mas, a fim de disfarçar o lado heteróclito de sua composição, Ibsen, ao longo da escrita da obra, teria tido a ideia de pressentir uma atriz entre suas amigas para ela ilustrar-se naquele papel. A fama brilhante daquela atriz dava assim uma forte garantia da futura audiência da peça. O sueco vê aí uma astúcia diplomática! O êxito obtido não terá dado "razão" a Ibsen? É bem provável. Porque aquela obra se tornou "um código para todos os defensores da emancipação da mulher".

A manobra atingiu seus objetivos além de toda esperança. Segundo Strindberg, os escandinavos se puseram a interpretar a realidade social convertendo-se aos julgamentos de valor suscitados pelo êxito de "Casa da boneca". Graças à orquestração dos "defensores da emancipação", esta maneira de julgar feminista se gravou na alma do público. Este se submeteu como se se tratasse de uma norma imperiosa. Uma profunda mutação do olhar sobre os seres humanos se impôs: fez-se como se a realidade tivesse de se submeter àquela norma com o risco de deturpar o significado daquilo que nela se vê: "toda mulher indolente e mentirosa era uma Nora, todo marido era um Helmer. Apenas se viam mulheres nobres oprimidas e homens vis e tirânicos. Os demais não se viam."25

Sobre as bases de tal desmistificação, depois de ter estabelecido que o favor com que foi creditada provém do acolhimento falseado duma peça já de si muito artificial, Strindberg pôde então desenvolver amplamente sua própria crítica. Mostra que não dá, no que lhe concerne, nenhuma fé à fraqueza do sexo reputado fraco.

25 STRINDBERG. Le fils de la servante, IV L'écrivain. In: OEuvre Autobiographique, op. cit., pp. 810-811.

314 I Cad. Nietzsche, São Paulo, v.36 n.1, p. 305-319, 2015. 
Propõe estabelecer que a mulher, hoje «tornada culta» através de uma cultura corruptora, se julga oprimida pelo homem nas relações conjugais, embora não o seja tanto como parece ${ }^{26}$.

As convergências entre as visões de Strindberg e as de Nietzsche se definem. Como o indicamos, foi meditando na obra dramática do sueco, $\mathrm{Pai}^{27}$, que o filósofo se interessou mais particularmente pelo trabalho do escritor $^{28}$. Sombria, implacável, esta peça não deixa lugar a outro desfecho senão à derrocada final. Tudo se passa como se Strindberg descobrisse o fundo do cenário, revelando-nos os mecanismos de uma tensão polêmica mal analisada por Ibsen. O trágico de Strindberg situa-se assim nas antípodas da obra do norueguês. A tragédia apresenta as peripécias dum terrível conflito entre duas vontades decididamente rivais. Trata-se da competição para o poder que opõe um homem $(O$ capitão $)$ e sua esposa (Laura) no seio dum matrimônio formado de longa data. Mas, aqui, a proximidade conjugal não exclui em nada a livre expressão das dissensões mútuas. As duas personagens não hesitam em se falar com certa rudeza. O litígio nasce a propósito da educação da filha.

No fim dessa luta sem piedade, na qual os próximos intervêm continuamente, sobretudo instigados com malícia pela esposa, é ela que consegue magistralmente impor seu ponto de vista. Primeiro, ela enfraquece "psicologicamente" o capitão. Graças ao artifício que consiste em lançar no seu espírito uma profunda dúvida sobre a legitimidade de sua paternidade altamente reivindicada, ela consegue pô-lo pouco a pouco sob sua tutela psíquica: daí, ele acaba por resmungar "ideias fixas". Laura consegue, na sequência de um ato de violência do marido que ela excedera, jogos todos os próximos contra ele. De fato, tendo suscitado a dúvida quanto a seu

26 STRINDBERG. Mariés!, op. cit., p. 12.

27 STRINDBERG. Théâtre complet 2, Ed. de l'Arche 1982, pp. 229-280.

28 Na sua carta ao escritor sueco de 27 de novembro de 1888 (n¹160, KGB III/5.493), Nietzsche afirma que leu duas vezes a obra e ficou profundamente comovido, "enormemente surpreendido". 
equilíbrio mental e divulgado a notícia do perigo que representa para todos, ela arranja um hábil estratagema para lhe vestirem a camisa-de-força. Todos estão convencidos da loucura dele. Neutralizado, aniquilado, ele fica irremediavelmente abatido ${ }^{29}$.

Vejamos como Nietzsche considera a "força da fraqueza" feminina $^{30}$ : trata-se de definir a vantagem de que se apoderou a "mulher", na competição incessante para a primazia. A fórmula de Nietzsche, aparentemente paradoxal, deve ser explicada. Não significa que a mulher esteja totalmente isenta de fraquezas, mas que ela conseguiu explorar uma convicção: como todos à sua volta estão convencidos da fragilidade feminina e persuadidos do imperioso dever de apoio ao fraco que daí resulta, aquela opinião provoca uma falência geral de lucidez. O grau exato daquela fraqueza não é visto como tal. Ora, segundo Nietzsche, as mulheres sentem mais ou menos instintivamente que há nisso algo que lhes é favorável. Elas se vingam, aproveitando de seus poderes de sugestão: "Todas as mulheres são sutis ao exagerarem as suas fraquezas, são mesmo inventivas quando se trata de fraquezas para se apresentarem apenas como ornamentos frágeis a que até um grãozinho de pó causa dor". (FW/GC, 66, KSA 3.426) ${ }^{31}$ É por aí que se tornam superiores àqueles que são supostos serem mais fortes do que elas.

Justamente, a heroína de Pai encarna uma daquelas mulheres que sabem tirar proveito com maestria daquela credulidade. Ela explora até o fim a falta de clarividência masculina e capta a benevolência de todos a seu respeito. A tal ponto que consegue ser obedecida sem ter de solicitar formalmente a obediência.

É possível conceber mais nitidamente a afinidade intelectual entre os dois homens. Para isso, contentar-nos-emos com uma

29 Cf. ATTALI, P. "Par-delà tout ce qu'on a vu dans L' 'amour" In: Nietzsche-Studien 42 (2013), p. 138, nota 58.

30 Referimos neste ponto ao aforismo 66 de A Gaia Ciência: A força dos fracos. Cf: FW/GC, 66, KSA 3.426.

31 Trad. In: F. Nietzsche, a Gaia Ciência, trad. de M.H. Rodrigues de Carvalho e M.L. de Almeida, Obras escolhidas de Friedrich Nietzsche, vol.3, Relógio d'água, Lisboa 1998.

316 | Cad. Nietzsche, São Paulo, v.36 n.1, p. 305-319, 2015. 
hipótese: se as almas de Nietzsche e de Strindberg se encontram profundamente sobre temas tão polêmicos, não será em razão de uma suspeita que compartilham e que os leva a pensar à parte? Os dois homens lançam, de fato, uma dúvida profunda sobre a validade intelectual de todas as "ideias modernas" que fazem a promoção da igualdade dos sexos. Parece que desconfiam da submissão daqueles ideais aos poderes mistificadores da fraqueza feminina evocada na peça de Strindberg. As questões irritantes que põem à modernidade são as seguintes: será que a vontade dos modernos em reparar as "injustiças" do passado e em emancipar o «sexo fraco" assenta, no fim das contas, sobre uma espécie de engano? Não terão caído na armadilha de uma manipulação feminina de sua culpabilidade em relação a fraquezas em parte infundadas? Ou seja, de fraquezas que eles teriam of fraco de levar demasiadamente a sério?

A proximidade dos pontos de vista dos nossos dois autores revela-se então significativa. Esta consideração não deve, contudo, esconder outros aspectos de sua relação. Divergências existem. Numa carta de 4 de dezembro de 1888, por exemplo, uma séria controvérsia aparece. Strindberg diz ao filósofo, no seu francês aproximativo: "Vous vous êtes leurré du type criminel! (Você enganou-se do tipo criminal!)» ${ }^{32}$ Ao que Nietzsche responde com uma análise tipológica muito matizada, que expõe a Strindberg e que encontramos no Crepúsculo dos ídolos (GD/CI, Incursões de um extemporâneo 45, KSA 6.146-148).

Os desacordos não devem ser subestimados. Contudo, parece-nos que seria redutor vermos em Strindberg um discípulo efêmero ou um aluno indócil de Nietzsche. Uma forma de amizade provavelmente nasceu apesar de sua oposição e da brevidade de sua relação.

32 STRINDBERG. Correspondance II, op. cit., p. 222; e Cahier de l'Herne, op. cit., p. 148. 
Attali, P.

É o encontro singular de duas almas à parte. Tentamos, neste estudo, levantar um pouco o misterioso véu que envolve este encontro.

\begin{abstract}
We intend to determine the philosophical interest of the correspondence between Friedrich Nietzsche and August Strindberg. Their destinies intersect because of a community of opinions on essentially polemical subjects: so they question the modern ideals of feminine emancipation. To show the signification of this delicate fight, we examine the controversy which Strindberg commits against a play of Ibsen, A Doll's House. Thanks to this analysis, it's, for us, possible to propose an interpretation of a great tragedy of Strindberg (The Father), to conceive clearly the specifically nietzschean sense of that work, and to show finally the limits of the intellectual convergence between both men.
\end{abstract}

Keywords: letters - fight - feminism - theatre - literature.

\title{
referências bibliográficas
}

ATTALI, P. “Par-delà tout ce qu'on a vu dans L' ‘amour”' In: Nietzsche-Studien 42 (2013), pp. 116-150.

BALZAMO, Elena (dir.). Strindberg Cahier de l'Herne. Paris, Éditions de l'Herne 2000 :

Le texte intégral de la correspondance entre Nietzsche et Strindberg est présenté aux pages 147 à 152 de cet ouvrage, dans une traduction d'Elena Balzamo. $C f$ : PERELLI Franco, Strindberg : l'expérience du surhomme, p. 135-146.

HÉMERY, Jean-Claude. Notes et variantes de Ecce homo. In: Nietzsche: L'Antéchrist suivi de Ecce homo, Éditions Gallimard 1974

IBSEN, Henrik. Une maison de poupée, Trad. R. Boyer. Paris Éditions Gallimard 20062013. Résumé de la pièce par Régis BOYER p. 286-287.

JANS, Curt Paul. Nietzsche. Biographie. tome III Les dix années du libre philosophe Printemps 1879 - décembre 1888. Trad. P. Rusch \& M. Vallois. Éd. Gallimard NRF 1985, Paris.

NIETZSCHE, Friedrich. Sämtliche Werke. Kritische Studienausgabe (KSA). Berlim: Walter de Gruyter \& Co., 1967/1978. 15 vols. (Organizada por Giorgio Colli e Mazzino Montinari).

Sämtliche Briefe. Kritische Studienausgabe (KGW). Berlim: Walter de Gruyter \& Co., 1986. 8 vols. (Organizada por Giorgio Colli e Mazzino Montinari).

318 I Cad. Nietzsche, São Paulo, v.36 n.1, p. 305-319, 2015. 
. A Gaia Ciência, trad. de M.H. Rodrigues de Carvalho e M.L. de Almeida, Obras escolhidas de Friedrich Nietzsche, vol.3, Relógio d'água, Lisboa 1998.

. O Anticristo seguido de Ecce homo, Edições Gallimard 1974, Trad. HÉMERY Jean-Claude, Cf: Notas e variantes de Ecce homo.

. Dernières Lettres - Hiver 1887-Hiver 1889. Traduction Y. Souladié. Ed. Manucius 2011.

PERELLI, F. Strindberg: l'expérience du surhomme. In Strindberg, Cahier de l'Herne sob a direção de E. Balzamo, Edições de l'Herne, 2000.

STRINDBERG, August. Correspondance II 1885-1894. Choix, présentation et traduction par Elena Balzamo, Paris Editions Zulma 2012.

Correspondance III 1894-1912. Choix, présentation et traduction par E. Balzamo. Paris Editions Zulma 2013.

. Le sacristain romantique de Rånö. Trad. E. Balzamo. Paris Ed. Viviane Hamy, 1999.

. Mariés ! I \& II Trad. Pierre Morizet et Eva Ahlstedt Arles Éditions Actes Sud Babel. 1986.

. Euvre Autobiographique Tomes I \& II. Edition établie et présentée par Carl Gustav Bjurström. Paris Éditions Mercure de France 1990.

_.,Théâtre complet 2, Trad. A. Adamov, Paris Éd. de l'Arche 1982 p. 229-280.

. Utopies dans la réalité. Trad. E. Balzamo et P. Morizet, Arles Ed. Actes Sud 2003

STRECKER Karl. Nietzsche und Strindberg. Georg Müller Verlag, München 1921.

WOTLING, P. Introduction au Crépuscule des idoles. Paris: Edição Flammarion, 2005.

Artigo recebido para publicação em 15/11/2014.

Artigo aceito para publicação em 22/02/2015.

Cad. Nietzsche, São Paulo, v.36 n.1, p. 305-319, 2015. 